\title{
Improvement of the electrochemical performance by partial chemical substitution into the lithium site of titanium phosphate-based electrode materials for lithium-ion batteries: $\mathrm{LiNi}_{0.25} \mathrm{Ti}_{1.5} \mathrm{Fe}_{0.5}\left(\mathrm{PO}_{4}\right)_{3}$
}

\author{
Mohammed Srout ${ }^{\mathrm{a}, \mathrm{b}}$, Mario El Kazzi ${ }^{\mathrm{c}}$, Hicham Ben Youcef $^{\mathrm{d}}$, Katharina M. Fromm ${ }^{\mathrm{b}}$, \\ Ismael Saadoune ${ }^{a, d, *}$ \\ ${ }^{a}$ IMED-Lab, Faculty of Science and Technology- Cadi Ayyad University, Av. A. El Khattabi, P.B.549, Marrakesh, Morocco \\ ${ }^{\mathrm{b}}$ University of Fribourg, Department of Chemistry, Chemin du Musee 9, CH-1700, Fribourg, Switzerland \\ ${ }^{\mathrm{c}}$ Electrochemistry Laboratory, Paul Scherrer Institute, CH-5232, Villigen, PSI, Switzerland \\ ${ }^{\mathrm{d}}$ Mohammed VI Polytechnic University, Lot 660-Hay Moulay Rachid, Ben Guerir, Morocco
}

H I G H L I G H T S

- $\mathrm{LiNi}_{0.25} \mathrm{Ti}_{1.5} \mathrm{Fe}_{0.5}\left(\mathrm{PO}_{4}\right)_{3} @ \mathrm{C}$ was successively prepared from $\mathrm{H}_{3} \mathrm{PO}_{4}$ acid.

- This phosphate exhibits the Nasicon-type structure.

- $\mathrm{Li} / / \mathrm{LiNi}_{0.25} \mathrm{Ti}_{1.5} \mathrm{Fe}_{0.5}\left(\mathrm{PO}_{4}\right)_{3} @ \mathrm{C}$ cell delivers a capacity of $108 \mathrm{mAh.g}{ }^{-1}$ at $5 \mathrm{C}$

- High capacity retention was obtained after 1000 cycles at $10 \mathrm{C}$ fast rate.

A R T I C L E I N F O

Keywords:

Li-ion batteries

NASICON structure

Phosphate materials

High rate-capability electrode

\begin{abstract}
A B S T R A C T
Partial lithium substitution with nickel $\left(0.25\right.$ of $\mathrm{Ni}^{2+}$ ion) in the previously reported $\mathrm{Li}_{1.5} \mathrm{Fe}_{0.5} \mathrm{Ti}_{1.5}\left(\mathrm{PO}_{4}\right)_{3} / \mathrm{C}$ (LFTP@C) was performed to improve its structural and electrochemical properties. The new $\mathrm{LiNi}_{0.25} \mathrm{Fe}_{0.5}$ $\mathrm{Ti}_{1.5}\left(\mathrm{PO}_{4}\right)_{3} / \mathrm{C}$ (LNFTP@C) material was then tested as electrode for lithium ion batteries. In the voltage window $1.85 \mathrm{~V}-3.0 \mathrm{~V} \mathrm{vs} . \mathrm{Li}^{+} / \mathrm{Li}$, attractive electrochemical performances were obtained, mostly in terms of rate capability performance. At a current rate of $0.1 \mathrm{C}\left(6.6 \mathrm{mAg}^{-1}\right)$, the material delivered a capacity of around $120 \mathrm{mAhg}^{-1}$, while at $5 \mathrm{C}$, we observed a slight drop of the specific capacity reaching a value of $108 \mathrm{mAhg}^{-1}$. Long-term cycling performance stability was also tested demonstrating a remarkable capacity decrease during the last 500 cycles. The capacity retention decreased from $94 \%$ to $91 \%$ after 500 cycles to about $77 \%$ and $74 \%$ after 1000 cycles at fast current rates of $5 \mathrm{C}\left(329.8 \mathrm{mAg}^{-1}\right)$ and $10 \mathrm{C}\left(659.6 \mathrm{mAg}^{-1}\right)$, respectively. In the wider voltage window, an average specific capacity of around $380 \mathrm{mAhg}^{-1}$ was attained at a slow current rate of $0.1 \mathrm{C}$.
\end{abstract}

\section{Introduction}

Electrochemical rechargeable batteries are considered as one of the leading technologies for electrical energy storage $[1,2]$. Moreover, they are considered as key element for the use and development of clean renewable energy sources, electric vehicles, and portable electronic devices [3-5]. Li-ion batteries (LIBs) stand as one of the very potential candidates because of their high energy density, but still suffer from some safety issues related mainly to the formation of dendrites and gas release $[6,7]$.
The energetic performances of LIBs depend mainly on the properties of its components, namely the anode, the cathode and the electrolyte. Regarding the anode, high capacity, high power and long-term cycling stability are the main electrochemical properties, which should be provided in order to build a powerful LIB satisfying the needs of the already mentioned applications [8].

Phosphate based NASICON materials, possessing very rich and various compositions, are one of the main families of materials other than the known carbonaceous one that have been investigated as potential anode materials for LIBs. Thanks to their attractive properties

\footnotetext{
* Corresponding author. IMED-Lab, Faculty of Science and Technology- Cadi Ayyad University, Av. A. El Khattabi, P.B.549, Marrakesh, Morocco.

E-mail address: i.saadoune@uca.ma (I. Saadoune).
} 
including the high structural and thermal stabilities, fast-ionic conductivity as well as low working voltages vs. $\mathrm{Li}^{+} / \mathrm{Li}(1.75$ and $2.5 \mathrm{~V}$ corresponding to the redox couples $\mathrm{V}^{3+} / \mathrm{V}^{2+}$ and $\mathrm{Ti}^{4+} / \mathrm{Ti}^{3+}$, respectively) [9-12], materials such as $\mathrm{Li}_{3} \mathrm{~V}_{2}\left(\mathrm{PO}_{4}\right)_{3}$ and $\mathrm{A}_{\mathrm{x}} \mathrm{Ti}_{2}\left(\mathrm{PO}_{4}\right)_{3}$, where "A" can be either monovalent $\left(\mathrm{Li}^{+}\right)$or divalent $\left(\mathrm{Ni}^{2+}, \mathrm{Mg}^{2+}, \mathrm{Ca}^{2+}\right.$, etc.) ions, have been investigated as anodes for LIBs $[9,13,14]$.

Regarding $\mathrm{LiTi}_{2}\left(\mathrm{PO}_{4}\right)_{3}$, a chemical substitution into the titanium (Ti) site using iron $(\mathrm{Fe})$ was first investigated by Catti et al., claiming an increase of lithium disorder in the NASICON structure, which may lead to better ionic conductivity [15], and therefore improved electrochemical properties. Moreover, substituting titanium with iron can have a positive effect regarding the electronic conductivity of this NASICON material. However, our previous investigation of the $\mathrm{Li}_{1.5} \mathrm{Fe}_{0.5}$ $\mathrm{Ti}_{1.5}\left(\mathrm{PO}_{4}\right)_{3}$ (LFTP) material as electrode for LIBs showed some very limited electrochemical performance [16].

In the present study, we propose a novel partial chemical substitution into the lithium site with the divalent ion $\mathrm{Ni}^{2+}$ in order to significantly improve the electrochemical properties of the already investigated LFTP@C compound. It is believed that the presence of $\mathrm{Ni}^{2+}$ in the lithium site helps to improve the structural stability and the electronic conductivity of this NASICON material, and it provides more vacant sites for lithium insertion into the structure, leading thus to enhanced specific capacity. Moreover, the presence of nickel results in optimizing the interstitial structural channels, which improves lithium diffusion in the NASICON structure and therefore leads to better electrochemical properties [17]. Accordingly, in this paper, we report our results related to the synthesis of a new NASICON-type electrode material LNFTP@C via the conventional sol-gel method, and the study of its structural, morphological and electrochemical properties.

\section{Experimental methods}

\subsection{Synthesis}

All chemical reagents were of analytical grade and were used without further purification. LNFTP was prepared via the sol-gel method by dissolving stoichiometric amounts of $\mathrm{Li}\left(\mathrm{OOCCH}_{3}\right) \cdot 2 \mathrm{H}_{2} \mathrm{O}(98 \%$; Sigma-Aldrich) $(7.75 \mathrm{mmol}), \mathrm{Ni}\left(\mathrm{OOCCH}_{3}\right)_{2} \cdot 4 \mathrm{H}_{2} \mathrm{O}$ (99.0\%; SigmaAldrich) (1.85 mmol), and $\mathrm{Fe}\left(\mathrm{NO}_{3}\right)_{3} \cdot 9 \mathrm{H}_{2} \mathrm{O}$ (98\%; Sigma-Aldrich) (3.69 mmol) in ethanol, then $\mathrm{H}_{3} \mathrm{PO}_{4}$ (85\%; Sigma-Aldrich) (9.64 $\mathrm{mmol})$ and $\mathrm{TiCl}_{4}$ solution (99\%; Aldrich) diluted in ethanol (11.08 mmol equivalent of $\mathrm{TiO}_{2}$ ) were added into the mixture. A homogenous solution was obtained and kept under magnetic stirring for $1 \mathrm{~h}$, then few drops of deionized water were added into the solution to adjust the $\mathrm{pH}$ $(\approx 0)$ in order to form a gel. The obtained gel was dried at $100{ }^{\circ} \mathrm{C}$ overnight, and subsequently grinded to get a powder. Next, the powder is heated at $400{ }^{\circ} \mathrm{C}$ with a heating rate of $5^{\circ} \mathrm{C} \mathrm{min}^{-1}$ for $3 \mathrm{~h}$, cooled down to room temperature and grinded for a second time using an agate mortar. Later, the powder was heated and kept at $680^{\circ} \mathrm{C}$ for $12 \mathrm{~h}$ under air atmosphere. In order to prepare the LNFTP@C composite, the resulting powder was grinded in a mortar with $15 \mathrm{wt} \%$ of sucrose in acetone. Afterwards, the mixture was dried and annealed at $600{ }^{\circ} \mathrm{C}$ for 6 $\mathrm{h}$ under argon flow.

\subsection{Characterizations}

The X-ray diffraction (XRD) patterns of the LNFTP@C were recorded using a Rigaku Ultima IV instrument with $\mathrm{Cu}-\mathrm{K} \alpha$ radiation $(\lambda=1.5406$ $\AA$ ). They were collected between $10^{\circ}$ and $60^{\circ}(2 \theta)$, with a step of $0.002^{\circ}$. The structural parameters were obtained by refining the diffraction data with the Rietveld method [18], using the FULLPROF program [19], with a pseudo-Voigt profile function to describe the shape of the diffraction lines. The morphology of the LNFTP@C material was observed by field emission scanning electron microscope (SEM, Tescan Mira3 LM FE) and transmission electron microscopy (TEM, Tecnai Spirit). The residual carbon content in the composite was determined by thermogravimetric analysis (TGA), with a heating rate of $10{ }^{\circ} \mathrm{C} \min ^{-1}$ using a Discovery TGA instrument under air atmosphere. The Raman spectra were recorded with a Witec alpha300RA confocal Raman system at room temperature und using a $532 \mathrm{~nm}$ beam in ambient air. The specific surface area of samples was obtained based on the adsorption-desorption isotherms of $\mathrm{N}_{2}$ at $77 \mathrm{~K}$ using an ASAP 2020 adsorption analyzer from Micromeritics. Before starting the measurements, the samples (weighting $\sim 500 \mathrm{mg}$ each) were outgassed at $200{ }^{\circ} \mathrm{C}$ for $12 \mathrm{~h}$. Then, the Brunauer-Emmett-Teller (BET) method [20] was applied to determine the specific surface area of the materials.

$\mathrm{X}$-ray photoelectron spectroscopy (XPS) analysis was conducted with a VG ESCALAB 220iXL spectrometer (Thermo Fisher Scientific) using focused monochromatized $\mathrm{Al} \mathrm{K} \alpha$ radiation $(1486.6 \mathrm{eV})$ with a beam size of $\sim 500 \mu \mathrm{m}^{2}$ (power of $150 \mathrm{~W}$ ). The pressure in the analysis chamber was approximately $2 \times 10^{-9}$ mbar. The spectrometer was calibrated on the clean silver surface by measuring the $\mathrm{Ag} 3 \mathrm{~d}_{5 / 2}$ peak at a binding energy (BE) of $368.25 \mathrm{eV}$ with a full width at half maximum (FWHM) of $0.78 \mathrm{eV}$. All the spectra were recorded under the conditions of $30 \mathrm{eV}$ pass energy and $50 \mathrm{eV}$ for the surveys in steps of $50 \mathrm{meV}$ and dwell time of 50 $\mathrm{ms}$. Control spectra were recorded at the beginning and at the end of each experiment as well as on different spots to ensure the reproducibility of the measurement and the homogeneity of the surface, and to certify that the sample did not evolve with time or suffer beam damage. The calibration of the binding energy peak positions is applied in this study using the conductive carbon signal in the $\mathrm{C} 1 \mathrm{~s}$ spectra located at $284.3 \mathrm{eV}$. After disassembling the cells in the glovebox, the electrodes were gently washed with dimethyl carbonate. An Ar-filled transfer chamber is used to transfer the samples to the XPS chamber to avoid air exposure and surface modification.

\subsection{Electrochemical measurements}

The electrochemical performance of the LNFTP@C samples were tested in half electrochemical coin cells (C2032 and C2016) by galvanostatic and cyclic voltammetry tests using a BioLogic MPG2, Arbin and Autolab (Metrohm autolab) instruments at room temperature.

The electrodes were prepared by mixing the active material (LNFTP@C), carbon black (super P), and Carboxymethyl Cellulose (CMC) dissolved in distilled water with a weight ratio of 75:15:10. Then, the prepared slurry is spread on copper foil ( $9 \mu \mathrm{m}$ thickness $)$ and dried at $80^{\circ} \mathrm{C}$. The mass loading of active material was around $1.8 \mathrm{mg} / \mathrm{cm}^{2}$. The electrodes were cut into small disks, then dried again under vacuum, to be finally transferred to an Ar-filled glove box (MBRAUN) with water and oxygen contents below $0.1 \mathrm{ppm}$ for battery assembly.

The electrochemical tests were performed using LNFTP@C as cathode and metallic lithium foil as anode. Commercial $\operatorname{LiPF}_{6}(1 \mathrm{M})$ dissolved in 50:50 ethylene carbonate (EC): dimethyl carbonate (DMC) was used as electrolyte and Celgard membrane as separator.

Electrochemical impedance spectroscopy (EIS) measurements were performed in order to follow the LNFTP@C electrode interface changes during the first cycle using an SP-150 BioLogic instrument.

\section{Results and discussion}

\subsection{Structure and morphology}

X-ray diffraction (XRD) has been used to determine the crystal structure of the as prepared LNFTP. As demonstrated in Fig. 1-(a), the diffraction pattern of the LNFTP powder shows that all the obtained peaks can be indexed within the rhombohedral symmetry, $R$-3c space group. Rietveld refinement has been also conducted in order to generate more detailed information related to the structure of the LNFTP material. The obtained results reveal a rhombohedral structure with lattice parameters $a=b=8.5051$ (4) $\AA, c=20.773$ (1) $\AA$ and a cell volume $V=$ 1301 (2) $\AA^{3}$. Note that the diffraction lines are relatively large indicating that the studied sample is composed from nano-sized particles. The small 

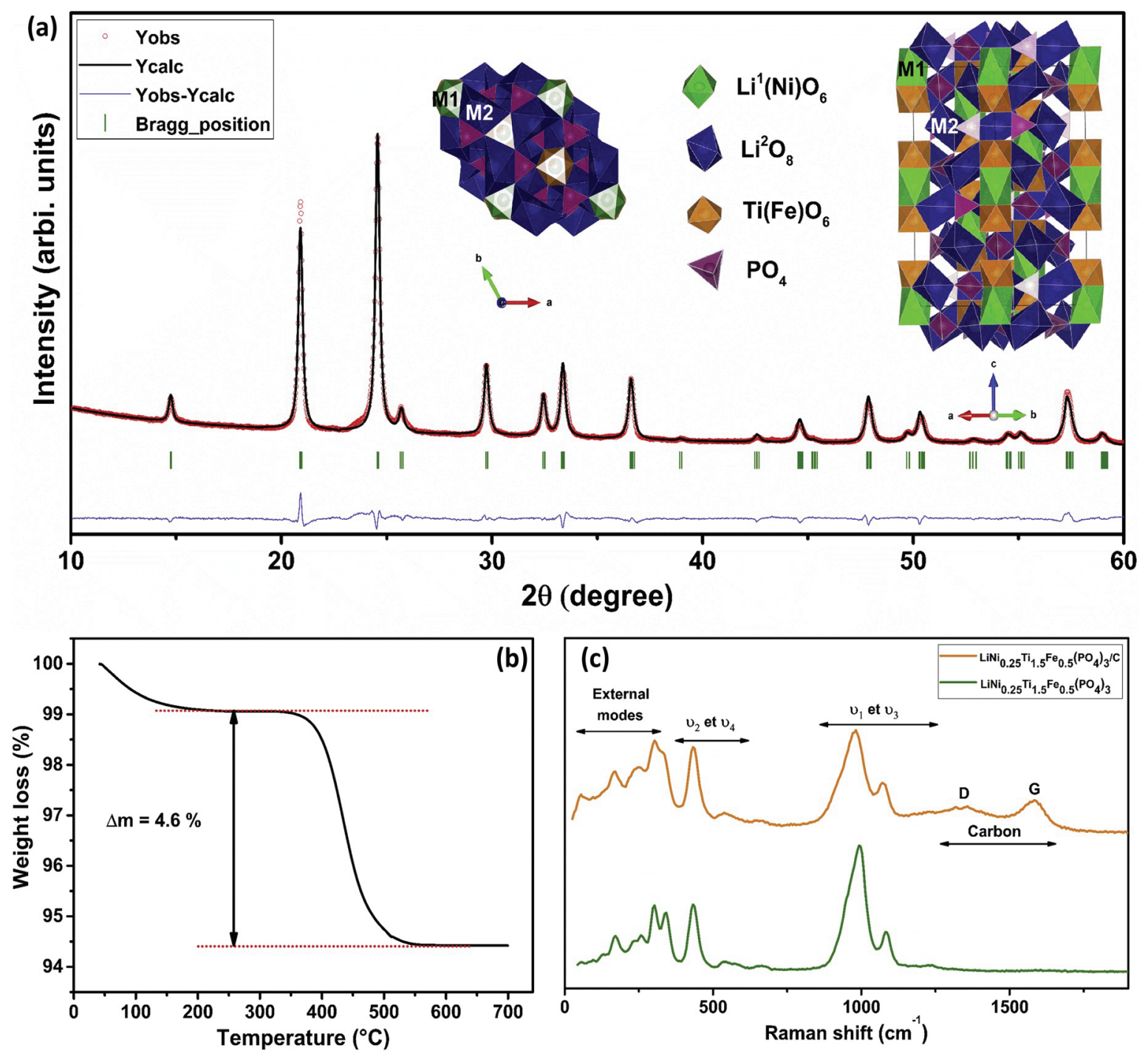

Fig. 1. (a) Rietveld refinement of the XRD pattern of LNFTP and its schematic structure; (b) Raman spectra of the LNFTP pristine and carbon coated powders; (c) TGA measurements of LNFTP@C composite.

values of the final obtained $\mathrm{R}_{\mathrm{wp}}$ and $\mathrm{R}_{\mathrm{p}}(<10 \%)$ suggest the validity of our refinement hypothesis, mainly that related to lithium-ions position in the structure. As demonstrated in the insert of Fig. 1-(a), lithium ions are considered to occupy two different sites. Li1, which is located in the M1 site together with Ni at the inversion symmetric Wyckoff position 6b and Li2, located at the less stable M2 site within the inversion symmetric Wyckoff position 18e as it was suggested in different related experimental and theoretical studies [21,22]. The LNFTP NASICON structure is constructed by the lantern-like units sequenced along the $c$-axis. Each unit is composed of $\mathrm{Ti}$ and $\mathrm{Fe}$ based octahedra $\left(\mathrm{Ti}(\mathrm{Fe}) \mathrm{O}_{6}\right)$ connected through the corners (O atoms) with $\left[\mathrm{PO}_{4}\right]$ tetrahedra (insert of Fig. 1-(a)). Tables SI-1 gives more detailed information on the calculated atomic positions in the LNFTP structure. Moreover, the obtained interatomic distances between the different anions and cations of LNFTP compound are given in Tables SI-2. These structural results are comparable to those obtained for $\mathrm{LiTi}_{2}\left(\mathrm{PO}_{4}\right)_{3}$ [23]. Even though, the LNFTP differs from the $\mathrm{LiTi}_{2}\left(\mathrm{PO}_{4}\right)_{3}$ through the presence of Li2 which occupy part of the free M2 sites with an average Li2-O distance of about 2.513 $\AA$. This value is comparable to that obtained for $\mathrm{Na} 2$ located in the same M2 site in the $\mathrm{Na}_{1.5} \mathrm{Ti}_{1.5} \mathrm{Fe}_{0.5}\left(\mathrm{PO}_{4}\right)_{3}$ material reported by Difi et al. [21]. When compared with the previously studied LFTP, a small lattice parameters decrease is observed for both $a(b)$ and $c$ parameters. Such a decreased can be related to the smaller ionic radius of $\mathrm{Ni}^{2+}(0.69 \AA)$ when compared to that of $\mathrm{Li}^{+}(0.76 \AA)$.

Raman spectroscopy has also been used on both pristine and carbon coated LNFTP materials (Fig. 1-(c)). The obtained Raman spectra of the bare LNFTP confirmed the NASICON structure of the studied material through the appearance of all NASICON-related vibrational modes [16]. The spectrum of the LNFTP@C composite reveals the presence of the same NASICON related characteristic modes and additional D and G bands located at around 1324 and $1587 \mathrm{~cm}^{-1}$ and confirming the presence of carbon in the LNFTP@C composite. Furthermore, TGA has been employed to quantify the amount of carbon in the LNFTP@C composite. As shown in Fig. 1-(b), the amount of carbon was determined to be around $4.6 \%$ of total weight. It is to note that the small mass loss at temperatures below $150{ }^{\circ} \mathrm{C}$ can be attributed to the adsorbed water loss from the sample. The specific surface area of both LNFTP and LNFTP@C was determined using the Brunauer-Emmett-Teller (BET) method and are $18.57 \mathrm{~m}^{2} \mathrm{~g}^{-1}$ and $22.59 \mathrm{~m}^{2} \mathrm{~g}^{-1}$, respectively.

SEM and TEM techniques have been used to investigate the morphology of the LNFTP@C composite. As demonstrated in Fig. 2-(a) and (b), SEM images reveal a nanosized morphology of the LNFTP@C particles. The composite LNFTP@C is composed mostly of irregular aggregates of nanosized particles possessing an almost spherical shape, with an average particle size of around $20-40 \mathrm{~nm}$. The high rates of agglomeration in the material are likely due to the high calcining 


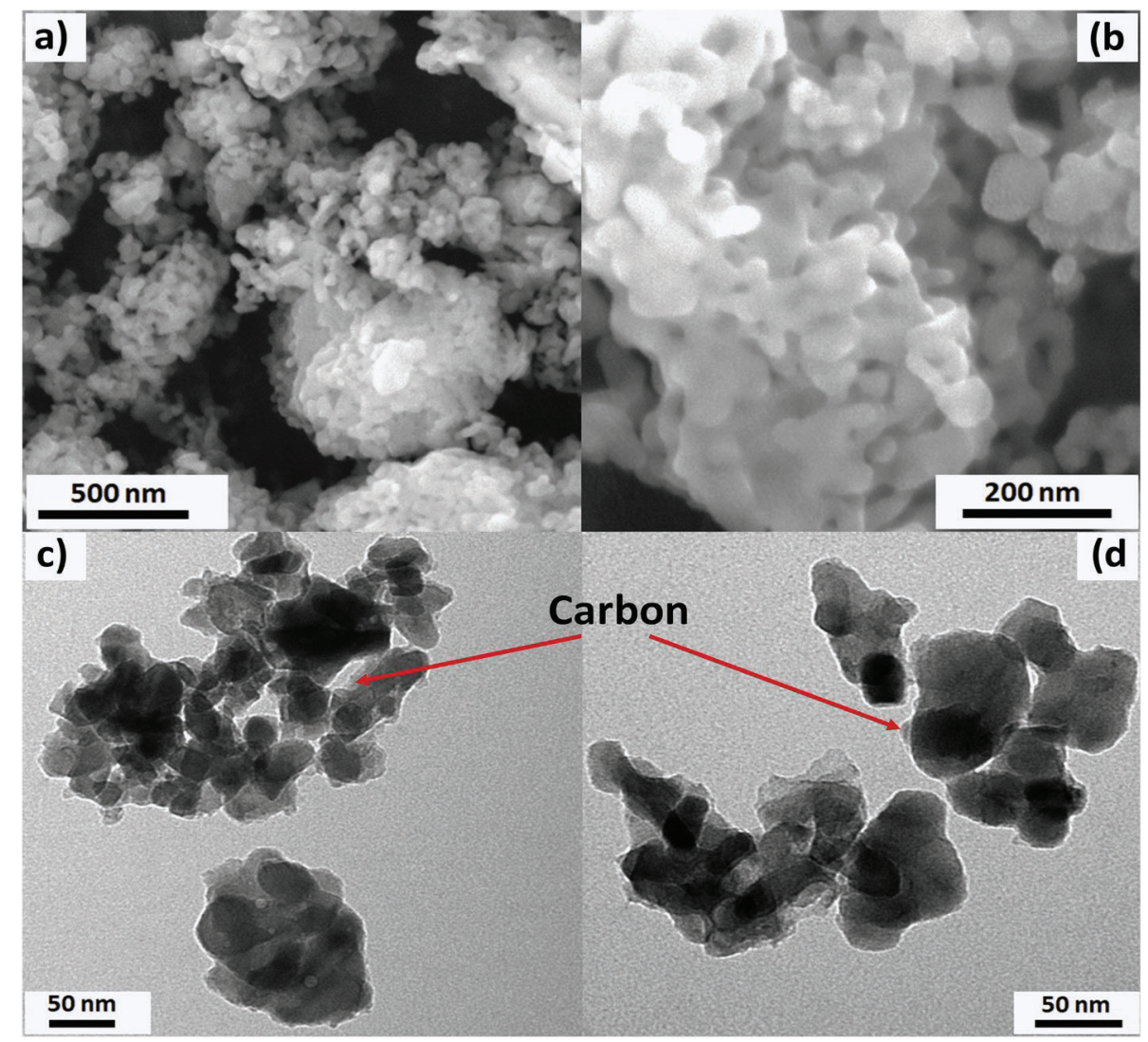

Fig. 2. (a) and (b): SEM images of the LNFTP@C material; (c) and (d) TEM images of the LNFTP@C composite.

temperature during the synthesis procedure.

Accordingly, TEM images of the LNFTP@C material were obtained (Fig. 2-(c) and (d)). These images confirm the morphology and particle size already observed via SEM and revealed how the LNFTP nanoparticles are embedded in the non-homogenous and amorphous carbon matrix. Both obtained pictures confirm the presence of a heterogeneous dense carbon layer on the surface of some LNFTP particles.

\subsection{Electrochemical performance}

In order to investigate the electrochemical properties of the LNFTP@C composite as electrode for LIBs, half coin cells were assembled using lithium metal as a counter electrode. The various conducted electrochemical tests were performed in two different voltage windows: $1.85-3.0 \mathrm{~V}$ and $0.5-3.0 \mathrm{~V}$.

\section{i) Potential window: $1.85-3.0 \mathrm{~V}$}

The first five galvanostatic charge-discharge profiles of the LNFTP@C electrode material versus $\mathrm{Li}^{+} / \mathrm{Li}$ between 1.85 and $3.0 \mathrm{~V}$ at a current rate of $0.1 \mathrm{C}\left(6.6 \mathrm{mAg}^{-1}\right)$ are shown in Fig. 3-(a). At this potential window, the small feature appearing at around $2.8 \mathrm{~V}$ is ascribed to the $\mathrm{Fe}^{3+} / \mathrm{Fe}^{2+}$ redox couple, while the clearly noticeable plateau appearing at $2.48 \mathrm{~V}$ is associated to the $\mathrm{Ti}^{4+} / \mathrm{Ti}^{3+}$ redox couple. The obtained galvanostatic profiles showed a reversible capacity of about $120 \mathrm{mAh} / \mathrm{g}$, which is about $91 \%$ of the theoretical capacity corresponding to the intercalation of $2 \mathrm{Li}^{+}$ions into the structure according the following reaction:

$$
\mathrm{LiNi}_{0.25} \mathrm{Ti}_{1.5}^{I V} \mathrm{Fe}_{0.5}^{I I I}\left(\mathrm{PO}_{4}\right)_{3}+2 \mathrm{Li}^{+}+2 e^{-} \rightarrow \mathrm{Li}_{3} \mathrm{Ni}_{0.25} \mathrm{Ti}_{1.5}^{I I I} \mathrm{Fe}_{0.5}^{I I}\left(\mathrm{PO}_{4}\right)_{3}
$$

The insert of Fig. 3-(a) shows the corresponding five CV cycles of the LNFTP@C electrode, between 1.85 and $3.0 \mathrm{~V} \mathrm{vs} \mathrm{Li} / \mathrm{Li}^{+}$at a slow scan rate of $0.02 \mathrm{mV} \mathrm{s}^{-1}$. Anodic and cathodic peaks showed a very reversible and stable behavior at this voltage range. The reversible cathodic and anodic peaks at around $2.8 \mathrm{~V}$ are mainly related to the reduction and oxidation of $\mathrm{Fe}\left(\mathrm{Fe}^{3+} / \mathrm{Fe}^{2+}\right)$, while those observed around $2.48 \mathrm{~V}$ are attributed to the redox reaction of $\mathrm{Ti}\left(\mathrm{Ti}^{4+} / \mathrm{Ti}^{3+}\right)$. These results are in good agreement with the galvanostatic ones, confirming the electrochemical behavior of the LNFTP@C electrode material.

In order to evaluate the electrochemical performance dependency of the LNFTP@C composite regarding the current density, an LNFTP@C electrode was cycled at different current rates, varying from 0.1C (6.6 $\mathrm{mAg}^{-1}$ ) to $5 \mathrm{C}\left(329.8 \mathrm{mAg}^{-1}\right)$ (Fig. 3-(b)). It was noticed that only a very small decrease of the discharge capacity is observed once the current rate is increased. A capacity around $120 \mathrm{mAhg}^{-1}$ was delivered at a slow current rate of $0.1 \mathrm{C}$. When the current rate is increased up to $5 \mathrm{C}$, a reversible specific capacity of about $108 \mathrm{mAhg}^{-1}(\approx 90 \%$ of the capacity obtained at $0.1 \mathrm{C}$ ) is delivered emphasizing the remarkable positive effect of lithium substitution with Ni in the previously reported LFTP@C material, while only a capacity around $42 \mathrm{mAhg}^{-1}$ (only $35 \%$ of the capacity obtained at $0.1 \mathrm{C}$ ) was reached once the current rate is increased to $5 \mathrm{C}[16]$.

Long-term cycling behavior is considered as one of the most important properties that electrode materials for LIBs should provide. Accordingly, in order to investigate the long-term cycling performance of the LNFTP@C electrode, cycling at high current rates such as 5C and 10C $\left(659.6 \mathrm{mAg}^{-1}\right)$ for 1000 cycles have been performed as shown in Fig. 3-(c). Reversible capacities of about 85 and $71 \mathrm{mAhg}^{-1}$ were obtained after 1000 cycles at current rates of 5C and 10C, respectively. Note that up to about 500 cycles, the capacity retention at both current rates $5 \mathrm{C}$ and $10 \mathrm{C}$ was around $94 \%$ and $91 \%$, respectively. Then a capacity fading was observed, to finally achieve a capacity retention of $77 \%$ at the current rate of $5 \mathrm{C}$ and $74 \%$ at the current rate of $10 \mathrm{C}$ after 1000 cycles. These performances are comparable to the ones obtained for our previously studied $\mathrm{Ni}_{0.5} \mathrm{Ti}_{2}\left(\mathrm{PO}_{4}\right)_{3} / \mathrm{C}$ compound [11]. 

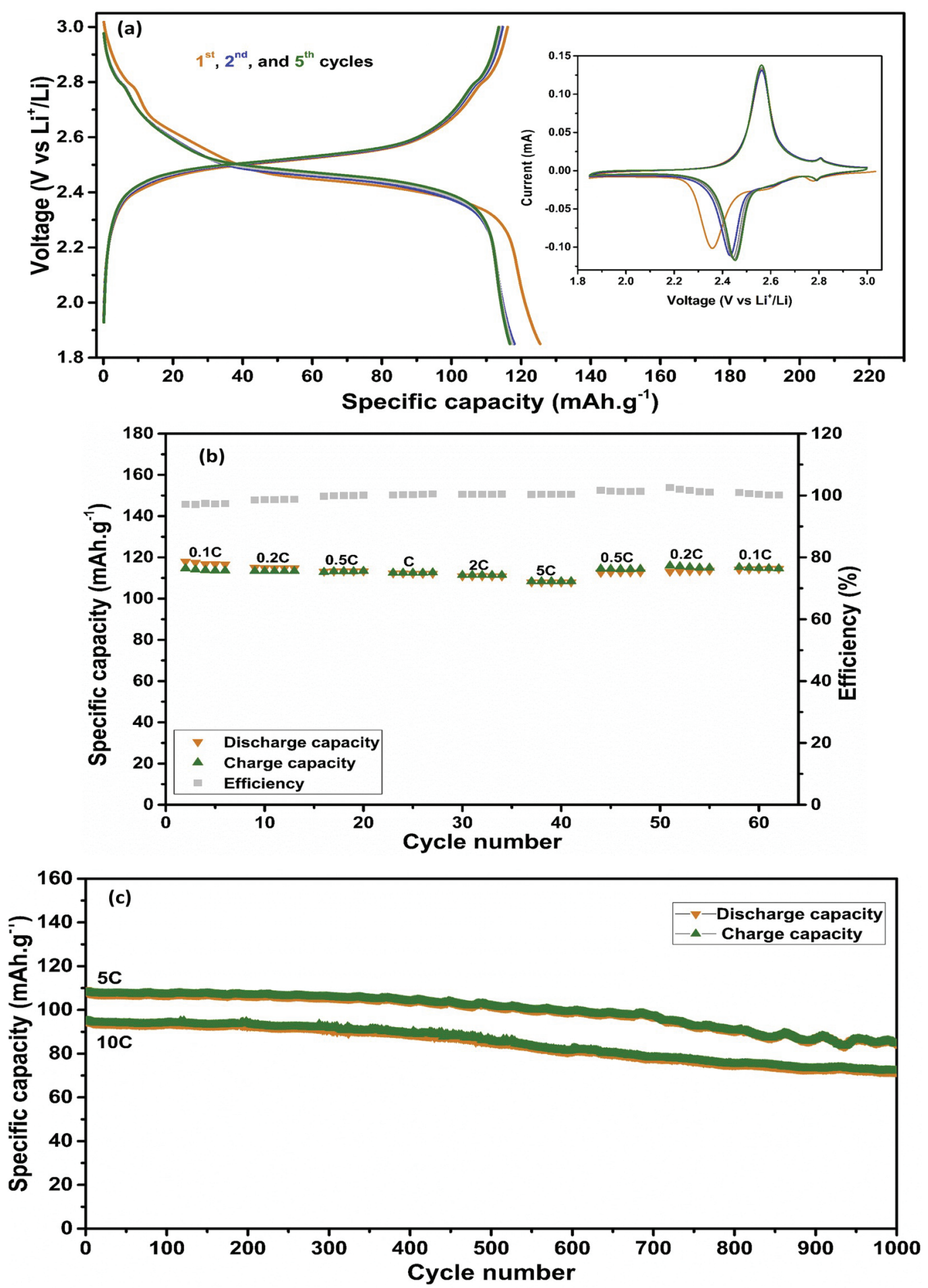

Fig. 3. Electrochemical properties of the LNFTP@C electrode material in the potential range 1.85 V-3V: (a) Charge-discharge profiles at 0.1C - Corresponding cyclic voltammetry at a scan rate of $0.02 \mathrm{mV} / \mathrm{s}$; (b) Rate capability at different current rates varying between $0.1 \mathrm{C}$ and $5 \mathrm{C}$; c) long-term cycling performance at fast current rates 5C (1000 cycles), and 10C (1000 cycles).

ii) Potential window: $0.5-3.0 \mathrm{~V}$

In order to assess the electrochemical properties of the $\mathrm{LNi}_{0.25} \mathrm{FTP} @ \mathrm{C}$ at lower voltage, a detailed electrochemical study of the $\mathrm{LNi}_{0.25} \mathrm{FTP} @ \mathrm{C}$ composite material was conducted between 0.5 and $3.0 \mathrm{~V}$. Fig. 4-(a) shows the galvanostatic charge-discharge profile of the $\mathrm{LNi}_{0.25} \mathrm{FTP} @ \mathrm{C}$ electrode at this voltage window at the current rate of 0.1C. Likely to the previously studied LFTP@C material [16], the first discharge profile was different from the subsequent ones.

The studied material delivered an excessive first discharge capacity of more than $740 \mathrm{mAhg}^{-1}$. This capacity dropped to about $390 \mathrm{mAhg}^{-1}$ after five cycles. Note that, except the first discharge, the galvanostatic profile of the charge/discharge cycles were almost identical. This observed difference in the galvanostatic profiles can be directly related to the structural rearrangements that took place during the lithiation process. To confirm this assumption, ex-situ XRD analysis was employed 

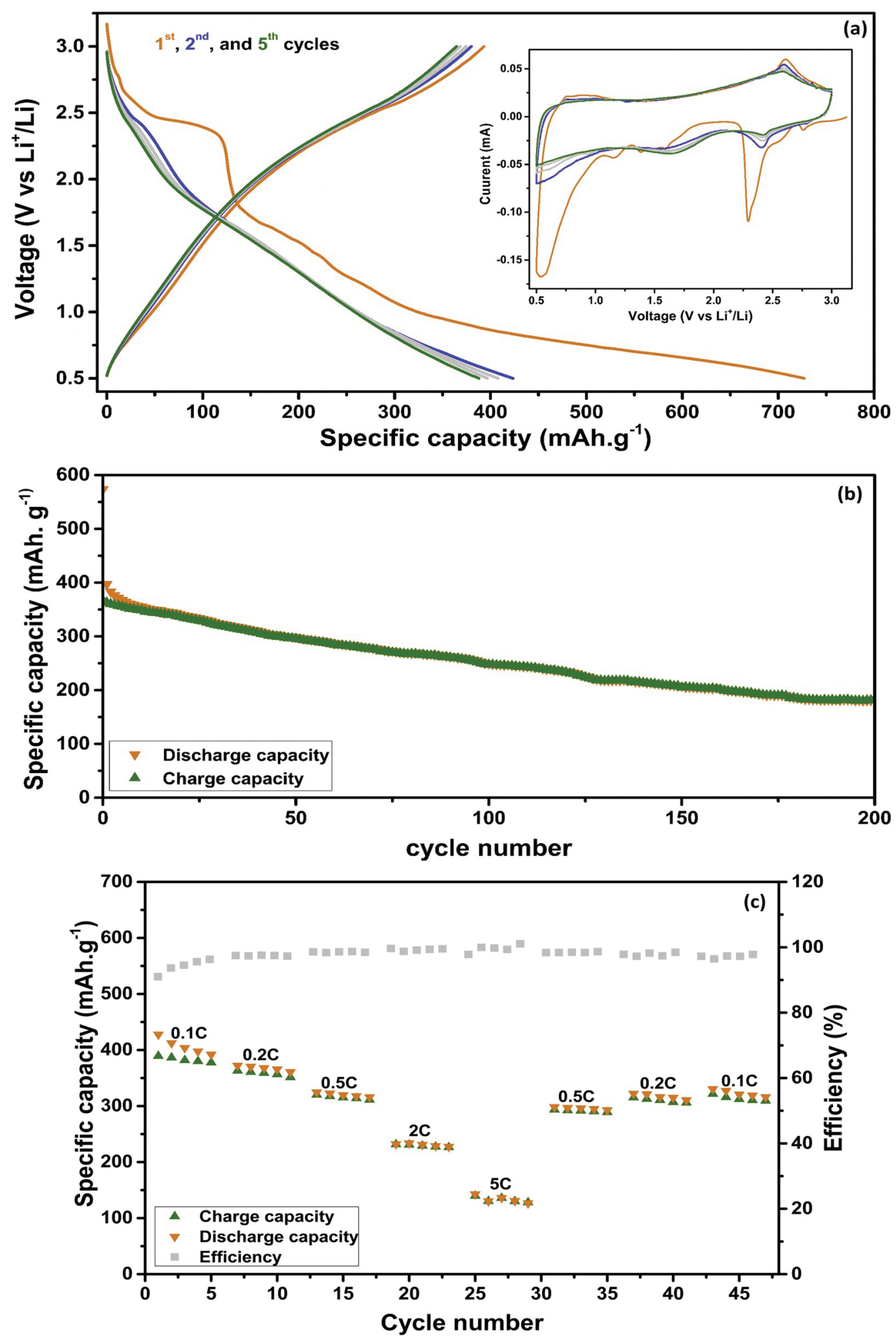

Fig. 4. Electrochemical properties of the LNFTP@C electrode material in the voltage range 0.5 V-3V: (a) Charge-discharge profiles at 0.1C - Corresponding cyclic voltammetry at a scan rate of $0.02 \mathrm{mV} / \mathrm{s}$; (b) long-term cycling performance at fast current rates 5C (1000 cycles), and 10C (1000 cycles); (c) Rate capability at different current rates varying between $0.1 \mathrm{C}$ and $5 \mathrm{C}$.

at different state of discharge-charge between 3.0 and $0.5 \mathrm{~V}$. As demonstrated in Fig. SI-1, the structural changes start occurring once we exceed $0.7 \mathrm{~V}$ during the discharge process. At the states of discharge OCV $, 1.85,1.0$ and $0.7 \mathrm{~V}$, the characteristic peaks related to the NASICON structure are still observed confirming the structural stability for potentials superior to $0.7 \mathrm{~V}$. Once the discharge voltage is around $0.5 \mathrm{~V}$, all characteristic peaks disappeared indicating strong structural changes in the structure of the active material leading to its complete amorphization. Once the electrode is charged back to $3.0 \mathrm{~V}$, no NASICON structure related peak was observed, confirming the irreversible 
structural rearrangement. These results are similar to the previously reported results of the LFTP@C and $\mathrm{Mg}_{0.5} \mathrm{Ti}_{2}\left(\mathrm{PO}_{4}\right)_{3}[10,16]$.

Based on these results, the reactional mechanism at this voltage range can be considered as following: First, a reduction of both $\mathrm{Fe}^{3+}$ to $\mathrm{Fe}^{2+}$ and then $\mathrm{Ti}^{4+}$ to $\mathrm{Ti}^{3+}$ as described in the previous section (1.85-3.0 potential window).

$\mathrm{LiNi}_{0.25} \mathrm{Ti}_{1.5}^{I V} \mathrm{Fe}_{0.5}^{I I I I}\left(\mathrm{PO}_{4}\right)_{3}+2 \mathrm{Li}^{+}+2 e^{-} \rightarrow \mathrm{Li}_{3} \mathrm{Ni}_{0.25} \mathrm{Ti}_{1.5}^{I I I} \mathrm{Fe}_{0.5}^{I I I}\left(\mathrm{PO}_{4}\right)_{3}$

The corresponding peaks of this redox reaction are observed around 2.8 and $2.48 \mathrm{~V}$, respectively, in the cyclic voltammogram curves shown in the insert of Fig. 4-(a). Then, at around $0.8 \mathrm{~V}$, a small shoulder can be seen, and it is attributed to the reduction of $\mathrm{Ti}^{3+}$ to $\mathrm{Ti}^{2+}$. Here, additional $1.5 \mathrm{Li}^{+}$are inserted to the structure exceeding the 4 vacant sites that are generally available in the NASICON structure. But as reported for the $\mathrm{Li}_{5} \mathrm{Fe}_{2}\left(\mathrm{PO}_{4}\right)_{3}$, there should be the possibility of hosting one more extra $\mathrm{Li}^{+}$in the NASICON structure without provoking detectable structural changes as we have confirmed via ex-situ XRD $[24,25]$.

$\mathrm{Li}_{3} \mathrm{Ni}_{0.25} \mathrm{Ti}_{1.5}^{I I I} \mathrm{Fe}_{0.5}^{I I}\left(\mathrm{PO}_{4}\right)_{3}+1.5 \mathrm{Li}^{+}+1.5 e^{-} \rightarrow \mathrm{Li}_{4.5} \mathrm{Ni}_{0.25} \mathrm{Ti}_{1.5}^{I I} \mathrm{Fe}_{0.5}^{I I}\left(\mathrm{PO}_{4}\right)_{3}$

It is to note that the observed small peaks between 1.8 and $1.0 \mathrm{~V}$ are attributed to the side reactions of the electrolyte resulting the SEI formation even though this phenomenon is known to take place bellow 1.0 $\mathrm{V}$. Cyclic voltammetry at both voltage ranges $3.0-1.5 \mathrm{~V}$ and then 3.0-1.0 V have confirmed this conclusion. As shown in Fig. SI-2, the irreversibility of these contributions after the first cycle is clearly demonstrated. Furthermore, EIS results (Fig. SI-3) have also confirmed the formation of the SEI layer once the LNFTP@C electrode is discharged to around $1.0 \mathrm{~V}$. Indeed, as shown in Fig. SI-3 and also confirmed through the obtained $\mathrm{R}$ values (Tables SI-3) obtained after fitting the Nyquist plots measured at different states of charge (OCV, $1.0 \mathrm{~V}, 0.5$, and back to $3.0 \mathrm{~V}$ ), an important increase of the cell impedance was observed once the electrode was discharged to about $1.0 \mathrm{~V}$, indicating the formation of the SEI layer. Afterwards, the impedance was almost conserved after discharging to around $0.5 \mathrm{~V}$ and then charging back to $3.0 \mathrm{~V}$.

Finally, a strong peak was observed between 0.6 and $0.5 \mathrm{~V}$, which corresponds to a new conversion reaction mechanism involving more $\mathrm{Li}^{+}$ions in the discharge process as well as some side reactions leading to the observed excessive first discharge capacity.

$\mathrm{Li}_{4.5} \mathrm{Ni}_{0.25} \mathrm{Ti}_{1.5}^{I I} \mathrm{Fe}_{0.5}^{\mathrm{II}}\left(\mathrm{PO}_{4}\right)_{3}+4.5 \mathrm{Li}^{+}+4.5 e^{-} \rightarrow 3 \mathrm{Li}_{3} \mathrm{PO}_{4}+0.25 \mathrm{Ni}+0.5 \mathrm{Fe}$

$+1.5 T i$

At this point, and corresponding to the three mentioned reactional mechanisms, a total of about $8 \mathrm{Li}^{+}$are exchanged in the $\mathrm{Li}^{+}$insertion process during the first discharge resulting in a theoretical capacity of about $528 \mathrm{mAhg}^{-1}$. The obtained extra capacity can be considered as a result of lithium consumption while forming the SEI layer.

To further investigate changes in the oxidation state of the different transitional metals in the LNFTP@C composition, post-mortem XPS measurements were carried out at different states of discharge/charge. Fig. SI-4. By comparing the pristine electrode with the cycled one, we observed that at $1.85 \mathrm{~V}, \mathrm{Fe}^{3+}, \mathrm{Ti}^{4+}$ ions get reduced to $\mathrm{Fe}^{2+}$ and $\mathrm{Ti}^{3+}$ respectively confirming the electrochemical reaction mechanism presented above. For both, pristine electrode, and the one discharged to $1.85 \mathrm{~V}, \mathrm{PO}_{4}$ related peak is stable and no obvious change is observed. Slight electrolyte reduction is noticed at $1.85 \mathrm{~V}$, supported by the attenuation of the $\mathrm{C} 1 \mathrm{~s}$ component related to the $\mathrm{C}-\mathrm{C}$ bond of the conductive carbon. Moreover, additional components appear in the $\mathrm{C} 1 \mathrm{~s}$ located at high binding energy from the $\mathrm{C}-\mathrm{C}$ component associated with the electrolyte reduction by-products e.g. $(\mathrm{C}-\mathrm{H}, \mathrm{C}-\mathrm{O}, \mathrm{O}-\mathrm{C}=\mathrm{O}$ and $\mathrm{Li}_{2} \mathrm{CO}_{3}$ ). At $0.5 \mathrm{~V}$, the electrolyte reduction is much pronounced with thicker SEI layer estimated around $5 \mathrm{~nm}$ covering both conductive carbon and TMs. This behavior is supported by the strong attenuation of the C-C component signal, as well as, the TMs signals which are in the noise level. The thick SEI makes the evaluation of the TMs oxidation at
$0.5 \mathrm{~V}$ very challenging. Then after charging back to $3.0 \mathrm{~V}$, the signals of the $\mathrm{C}-\mathrm{C}$ component and the TMs recover slightly confirming the partial dissolution of the SEI. Based on the binding energy of the Fe2p and Ti2p core levels, some irreversibility in term of the oxidation states is observed confirming the structural rearrangement demonstrated using the ex-situ XRD. A mixed oxidation state of $\mathrm{Fe}^{2+}$ and $\mathrm{Fe}^{3+}$, and $\mathrm{Ti}^{4+}$ and $\mathrm{Ti}^{3+}$ is noticed.

As shown in Fig. 4-(b), long-term cycling performance at the fast current rate of $5 \mathrm{C}$ was examined at this potential window. Here, a capacity fading was clearly observed. After 200 cycles, only a capacity retention of about $45 \%$ was achieved. Moreover, the rate capability performance of the LNFTP@C electrode at this voltage range was also tested. As demonstrated in Fig. 4-(c), the material showed a very low performance when switching from low to high current rates. At $0.1 \mathrm{C}$, a specific capacity around $390 \mathrm{mAhg}^{-1}$ was delivered. This capacity dropped to less than $120 \mathrm{mAhg}^{-1}$ when the electrode is cycled at a current rate of $5 \mathrm{C}$. Once the current rate was decreased again to $0.1 \mathrm{C}$, an increased capacity of more than $300 \mathrm{mAhg}^{-1}$ was recovered.

\section{Conclusion}

LNFTP@C composite with nano-sized primary particles has been successfully synthesized via a simple sol-gel method followed by a carbon-coating process using sucrose as carbon-source. When tested as electrode material for LIBs, the LNFTP@C composite showed very promising and stable results in a voltage window of 1.85-3.0 V with remarkable rate capability performance. The obtained electrochemical properties at this voltage window are remarkably superior to the ones obtained for the LFTP@C where no Ni is introduced, highlighting the positive influence of cationic substitution into the Li (M1) site. At lower voltage range (0.5-3.0 V), inferior electrochemical performances were obtained, mainly due to the irreversible structural rearrangement that took place as a result of the massive lithium insertion into the structure. Ex-situ XRD and XPS confirmed this irreversibility which occurs once the discharge voltage $0.5 \mathrm{~V}$ is reached.

\section{Declaration of competing interest}

The authors declare that they have no known competing financial interests or personal relationships that could have appeared to influence the work reported in this paper.

\section{CRediT authorship contribution statement}

Mohammed Srout: Formal analysis, Supervision, Writing - original draft. Mario El Kazzi: Formal analysis. Hicham Ben Youcef: Supervision, Writing - review \& editing. Katharina M. Fromm: Supervision. Ismael Saadoune: Writing - original draft.

\section{Acknowledgements}

This work was done with the financial support of OCP group (Morocco) through the APPHOS Program (2017-2019). The authors further thank the Swiss Confederation for the excellence stipend for M. Srout, the University of Fribourg and the Swiss National Science Foundation as well as the Adolphe Merkle Foundation (FriMat) for generous support.

\section{Appendix A. Supplementary data}

Supplementary data to this article can be found online at https://doi. $\operatorname{org} / 10.1016 /$ j.jpowsour.2020.228114. 


\section{References}

[1] A.B. Gallo, J.R. Simões-Moreira, H.K.M. Costa, M.M. Santos, E. Moutinho dos Santos, Energy storage in the energy transition context: a technology review, Renew. Sustain. Energy Rev. 65 (2016) 800-822, https://doi.org/10.1016/j. rser.2016.07.028.

[2] M.S. Guney, Y. Tepe, Classification and assessment of energy storage systems, Renew. Sustain. Energy Rev. 75 (2017) 1187-1197, https://doi.org/10.1016/j. rser.2016.11.102.

[3] M.S. Whittingham, Lithium batteries and cathode materials, Chem. Rev. 104 (2004) 4271-4302, https://doi.org/10.1021/cr020731c.

[4] B. Scrosati, J. Hassoun, Y.-K. Sun, Lithium-ion batteries. A look into the future, Energy Environ. Sci. 4 (2011) 3287, https://doi.org/10.1039/c1ee01388b.

[5] E. Karden, S. Ploumen, B. Fricke, T. Miller, K. Snyder, Energy storage devices for future hybrid electric vehicles, J. Power Sources 168 (2007) 2-11, https://doi.org/ 10.1016/j.jpowsour.2006.10.090.

[6] L. Lu, X. Han, J. Li, J. Hua, M. Ouyang, A review on the key issues for lithium-ion battery management in electric vehicles, J. Power Sources 226 (2013) 272-288, https://doi.org/10.1016/j.jpowsour.2012.10.060.

[7] G. Zubi, R. Dufo-López, M. Carvalho, G. Pasaoglu, The lithium-ion battery: state of the art and future perspectives, Renew. Sustain. Energy Rev. 89 (2018) 292-308, https://doi.org/10.1016/j.rser.2018.03.002.

[8] W.M. Zhang, X.L. Wu, J.S. Hu, Y.G. Guo, L.J. Wan, Carbon coated $\mathrm{Fe}_{3} \mathrm{O}_{4}$ nanospindles as a superior anode material for lithium-ion batteries, Adv. Funct. Mater. 18 (2008) 3941-3946, https://doi.org/10.1002/adfm.200801386.

[9] Q. Fu, S. Liu, A. Sarapulova, L. Zhu, M. Etter, E. Welter, P.G. Weidler, M. Knapp, H. Ehrenberg, S. Dsoke, Electrochemical and structural investigation of calcium substituted monoclinic $\mathrm{Li}_{3} \mathrm{~V}_{2}\left(\mathrm{PO}_{4}\right)_{3}$ anode materials for Li-ion batteries, Adv. Energy Mater. 9 (2019), https://doi.org/10.1002/aenm.201901864, 1901864.

[10] Y. Zhao, Z. Wei, Q. Pang, Y. Wei, Y. Cai, Q. Fu, F. Du, A. Sarapulova, H. Ehrenberg B. Liu, G. Chen, NASICON-type $\mathrm{Mg}_{0.5} \mathrm{Ti}_{2}\left(\mathrm{PO}_{4}\right)_{3}$ negative electrode material exhibits different electrochemical energy storage mechanisms in Na-ion and Li-ion batteries, ACS Appl. Mater. Interfaces 2 (2017), https://doi.org/10.1021 acsami.6b14196 acsami.6b14196.

[11] M. Srout, N.H. Kwon, W. Luo, A. Züttel, K.M. Fromm, I. Saadoune, New $\mathrm{Ni}_{0.5} \mathrm{Ti}_{2}\left(\mathrm{PO}_{4}\right)_{3} @ \mathrm{C}$ NASICON-type electrode material with high rate capability performance for lithium-ion batteries: synthesis and electrochemical properties, ChemSusChem (2019), https://doi.org/10.1002/cssc.201902002 cssc.201902002.

[12] G.X. Wang, D.H. Bradhurst, S.X. Dou, H.K. Liu, $\mathrm{LiTi}_{2}\left(\mathrm{PO}_{4}\right)_{3}$ with NASICON-type structure as lithium-storage materials, J. Power Sources 124 (2003) 231-236, https://doi.org/10.1016/S0378-7753(03)00609-8.
[13] X.H. Rui, N. Yesibolati, C.H. Chen, $\mathrm{Li}_{3} \mathrm{~V}_{2}\left(\mathrm{PO}_{4}\right)_{3} / \mathrm{C}$ composite as an intercalationtype anode material for lithium-ion batteries, J. Power Sources 196 (2011) 2279-2282, https://doi.org/10.1016/j.jpowsour.2010.09.024.

[14] V. Aravindan, W.C. Ling, S. Hartung, N. Bucher, S. Madhavi, Carbon-coated $\mathrm{LiTi}_{2}\left(\mathrm{PO}_{4}\right)_{3}$ : an ideal insertion host for lithium-ion and sodium-ion batteries, Chem. Asian J. 9 (2014) 878-882, https://doi.org/10.1002/asia.201301461.

[15] M. Catti, A. Comotti, S. Di Blas, R.M. Ibberson, Extensive lithium disorder in $\mathrm{Li}_{1.5} \mathrm{Fe}_{0.5} \mathrm{Ti}_{1.5}\left(\mathrm{PO}_{4}\right)_{3}$ Nasicon by neutron diffraction, and the $\mathrm{Li}_{1+\mathrm{x}} \mathrm{Fe}_{\mathrm{x}} \mathrm{Ti}_{2-\mathrm{x}}\left(\mathrm{PO}_{4}\right)_{3}$ phase diagram, J. Mater. Chem. 14 (2004) 835-839, https://doi.org/10.1039/ B312865B.

[16] M. Srout, K. Lasri, M. Dahbi, A. Kara, L. Tetard, I. Saadoune, Understanding of the Li-insertion process in a phosphate based electrode material for lithium ion batteries, J. Power Sources 435 (2019), https://doi.org/10.1016/J. JPOWSOUR. 2019.226803, 226803.

[17] Z. Wu, Z. Xie, A. Yoshida, Z. Wang, X. Hao, A. Abudula, G. Guan, Utmost limits of various solid electrolytes in all-solid-state lithium batteries: a critical review, Renew. Sustain. Energy Rev. 109 (2019) 367-385, https://doi.org/10.1016/j. rser.2019.04.035.

[18] H.M. Rietveld, A profile refinement method for nuclear and magnetic structures, J. Appl. Crystallogr. 2 (1969) 65-71, https://doi.org/10.1107/ S0021889869006558.

[19] J. Rodríguez-Carvajal, Recent advances in magnetic structure determination by neutron powder diffraction, Phys. B Condens. Matter 192 (1993) 55-69, https:// doi.org/10.1016/0921-4526(93)90108-I.

[20] S. Brunauer, P.H. Emmett, E. Teller, Adsorption of gases in multimolecular layers, J. Am. Chem. Soc. 60 (1938) 309-319, https://doi.org/10.1021/ja01269a023.

[21] S. Difi, I. Saadoune, M.T. Sougrati, R. Hakkou, K. Edstrom, P. Lippens, Mechanisms and performances of $\mathrm{Na}_{1.5} \mathrm{Fe}_{0.5} \mathrm{Ti}_{1.5}\left(\mathrm{PO}_{4}\right)_{3} / \mathrm{C}$ composite as electrode material for Na-ion batteries, J. Phys. Chem. C 119 (2015) 25220-25234, https://doi.org/ 10.1021/acs.jpcc.5b07931.

[22] B. Lang, B. Ziebarth, C. Elsässer, Lithium ion conduction in $\mathrm{LiTi}_{2}\left(\mathrm{PO}_{4}\right)_{3}$ and related compounds based on the NASICON structure: a first-principles study, Chem. Mater. 27 (2015) 5040-5048, https://doi.org/10.1021/acs.chemmater.5b01582.

[23] I.Y. Pinus, A.V. Khoroshilov, K.S. Gavrichev, V.P. Tarasov, A.B. Yaroslavtsev, On cationic mobility in Nasicon phosphates $\mathrm{LiTi}_{2}\left(\mathrm{PO}_{4}\right)_{3}$ and $\mathrm{Li}_{0.9} \mathrm{Ti}_{1.9} \mathrm{Nb}_{0.1}\left(\mathrm{PO}_{4}\right)_{3}$, Solid State Ionics 212 (2012) 112-116, https://doi.org/10.1016/j.ssi.2012.01.035.

[24] C. Masquelier, L. Croguennec, Polyanionic (phosphates, silicates, sulfates) frameworks as electrode materials for rechargeable $\mathrm{Li}$ (or Na) batteries, Chem. Rev. 113 (2013) 6552-6591, https://doi.org/10.1021/cr3001862.

[25] H. Karami, F. Taala, Synthesis, characterization and application of $\mathrm{Li}_{3} \mathrm{Fe}_{2}\left(\mathrm{PO}_{4}\right)_{3}$ nanoparticles as cathode of lithium-ion rechargeable batteries, J. Power Sources 196 (2011) 6400-6411, https://doi.org/10.1016/j.jpowsour.2011.03.079. 